\title{
The cross border Agenda 21 as a governance tool
}

\author{
F. Pirlone, Z. Sotgia, I. Spadaro \& P. Ugolini \\ Faculty of Engineering, Genoa University, Italy
}

\begin{abstract}
This paper draws on research conducted within an EU program (Project ACTI.VE-Operational Programme Italy-France "Maritime" 2007-2013, cooperation area regions: Liguria, Tuscany and Corsica) and reports, besides the most significant results, further proposals and processing. The research goal is to define a cross border Agenda 21 as a tool for planning, development and sustainable management of the land on a transboundary level, to promote the best good practices for creating an Action Plan on Transboundary (PAT). Such actions are, in fact, the operational tool to achieve acceptable levels of sustainability. Each best practice, however, is "a product of its own territory" and is therefore difficult present it again "tout court" in the different territorial contexts.

In the first part, the analysis of the state of the art of Agenda 21 will be reported at different levels of scale, and the best practices identified (cognitive analysis), some of which were shared within international Forum. In this perspective, information, awareness, communication and training are essential steps of the participatory process (awareness both of the individual and the community of belonging), inherent in the process of Agenda 21. In the later stages, in order to make this process more effective, a methodological approach has been identified and a questionnaire prepared (for the four topics: waste, mobility and transport, energy and tourism) aimed at both enhancing the contributions of all partners and identifying the "applicability threshold" of best practices. The identification of the latter is essential today to support public administrations in choosing actions of planning, management and development, as well as monitoring, more suitable to their respective fields of competence.

Keywords: Agenda 21, action plan, best practices, participatory process, governance, sustainability.
\end{abstract}




\section{Introduction}

This paper draws on research carried out within an EU program (Project ACTI.VE-Operational Programme Italy-France "Maritime" 2007-2013, area of cooperation: Liguria, Tuscany and Corsica) and this paper also reports, besides the most significant results, further proposals and processing.

ACTI.VE "Action Verte" is a project of cross-border cooperation, presented and funded by the European Union under the Operational Programme ItalyFrance Maritime.

The project aims to contribute to developing guidelines for the realization of a plan for sustainable development and safeguarding the cross border area, with the view of Agenda 21 "inter-local".

The objective is therefore to create an institutional network to promote and capitalize on the experiences of best practices developed in the context of Agenda 21.

This is in order to foster a systematic comparison on the topics of sustainable development, protection and enhancement of environmental resources, management and disposal of municipal and industrial waste, methods and approaches of active participation of local stakeholders.

Contributors to the project are a multi-level partnership made up of local authorities belonging to the regions of Liguria, Tuscany and Corsica. This has considerable potential in order to improve the search for common solutions and sharing and comparing experiences in these areas. This is: Capannori Municipality (leader), Unione Comuni della Valdera, Departement de la Corse du Sud, CRUIE - Research Centre for Urbanism, Infrastructure and Ecology, University of Genoa, Lucense, Centre Association European Studies PLURAL.

The aim of the research here reported is the definition of a process of Agenda 21, at a cross border level, as a tool for planning, management and sustainable development. This tool is aimed at identifying and promoting the best good practices to be included in an Action Plan on Transboundary (APT), which means operating to achieve acceptable levels of sustainability.

First of all, it is useful to highlight the strong and widespread interest about the topical issues that the ACTI.VE project intends to address, both for the matter as for the levels of scale at which this is to apply: from cross-border level, that of "consortium of municipalities" and the urban reality (small, medium and large). All fields with its own characteristics and problems.

Globalization (cultural, social and economic) in recent decades has led to an increase in the processes of development and relevant changes, especially in urban systems, increasing environmental pressures. This puts in today, the need to weigh up the choices of governance within the broader framework of environmental sustainability and, moreover, to protect natural resources through strategic planning, and then to combine the economic and social development with no impoverishment of natural resources. This need was born from the 1970s with the introduction of a new regulatory framework and of new strategies and tools, mostly inspired by EU, for finding a balance in order to achieve a high 
level of quality of life from a social and economical point while preserving natural resources, territory, quality of life and health.

Especially, during the Stockholm Conference of 1972, for the first time, United Nations, at a global level, have made considerations on development and environment and have outlined the so-called model of sustainable development. Later, during the conference in Rio de Janeiro in 1992, the Agenda 21 tool like "Document of intent for the promotion of sustainable development" was introduced.

\section{The local Agenda 21 and the state of play}

It is not easy to find an immediate and clear definition of the local Agenda 21; it is defined rather as: "a mechanism, a path, a method of work, a technical and cultural proposal that lays the foundations to stimulate local activities aimed at achieving and verifying the local sustainable development objectives, shared with the local community" (Bishop J. Cards for BDOR limited: "UK guidance prepared by Local Government Management Board").

After the conference, Agenda 21 was adopted by 178 governments around the world (including Italy), as a document of intent for the promotion of sustainable development that, taking into account social, environmental and economic concerns, is able to catch in advance any items of incompatibility existing between the socio-economic activities and the politics of protection and environmental safeguards. Agenda 21 literally means: program of "things to do" for the twenty-first century "things to do" to translate into actions, the theoretical assumptions of sustainable development.

The Local Agenda 21 is the instrument to implement "sustainability actions" at a local level to which the Rio Declaration invited “... individual local communities to start up a process of consultation and consensus building among the social partners, in order to define and implement a Local Environmental Action Plan for urban sustainability addressed to the 21 st century ...."

From Rio to date, the Local Agenda 21 has been, for many local communities, the means by which they have developed action programs for sustainable development. Although the basic principles are defined, the implementation of the local Agenda 21 has been made along many different pathways related to the characteristics of the context within which it developed [1].

As we know, this is a voluntary instrument with very different methodological applications but based on building a participatory process. In fact, the different socio-economic actors are called by the administration, through a forum, to acknowledge and agree a framework of cognitive base (the Report on the State of the Environment), to define a coherent set of objectives and actions (the Action Plan of the Local Agenda 21), to assume the responsibility to implement the actions under its jurisdiction and, finally, to monitor the success of actions taken against objectives and to recalibrate the Action Plan [2].

The Local Agenda 21 is therefore a process of governance based on principles of subsidiarity (because it brings the decision-making level very close to the 
citizen); knowledge sharing and development objectives; of integration (since the mode is interdisciplinary and non-sectorial) but is also based on the principles of accountability and consistency for all parties involved in the process (fig. 1) [3].

LOCAL AGENDA 21

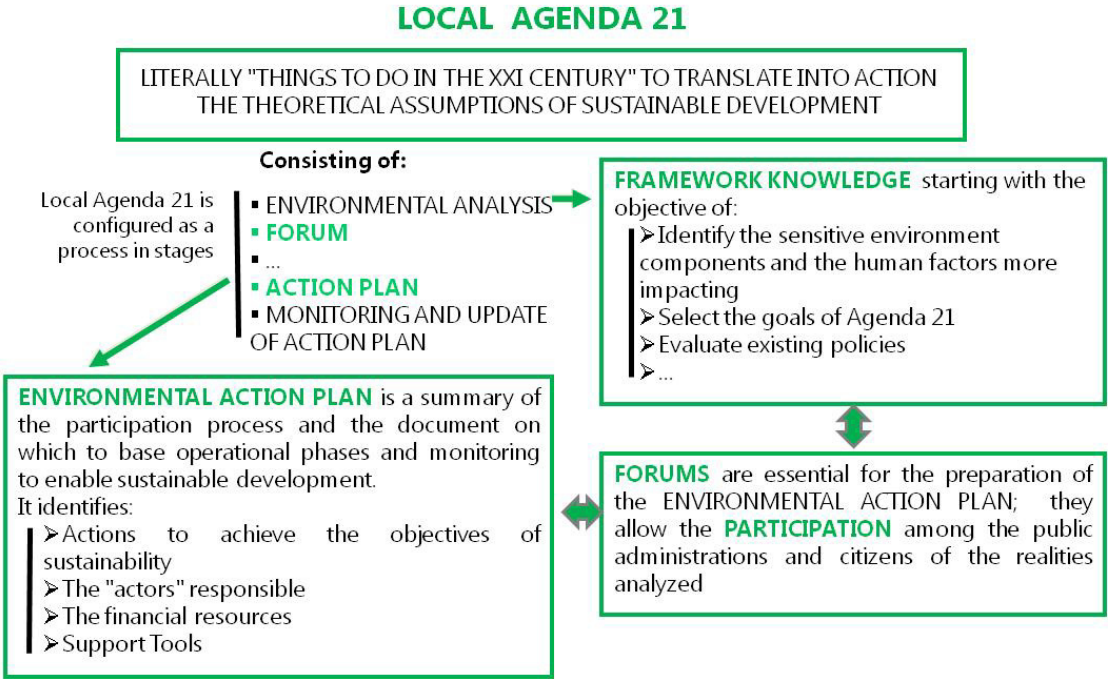

Figure 1: $\quad$ Local Agenda 21.

In this paper Agenda 21 is proposed as a tool for planning, development and sustainable land management, particularly at the urban level, able to develop an integrated view, useful to prevent conflicts due to actions taken unilaterally or sectorial. This process develops the dialogue and interaction between administration and citizens, by improving the understanding of mutual needs and possibilities of action, creating a virtuous circle of information, building networks and partnerships and the enhancement of social capital. It is suitable to achieve integration of plans and programs and, in general, to give coherence to the action of the Administration, in order to lead to medium-long term planning which pursues sustainability and durability of development, excluding destabilizing solutions.

The final goal of the Forum for Agenda 21 is the drafting of the Environmental Action Plan, which is the synthesis of the participatory process and the document on which to base the operational and monitoring phase.

Key aspects own of the Agenda 21, repeated over the years (Aalborg $1994-$ Alborg +10 2004 - European Conference on Sustainable Cities and Towns, Fifth European Conference on Sustainable Cities and Towns in Seville in 2007, Sixth European Conference on Sustainable Cities and Towns Dunkerque 2010) will be renewed at the Earth Summit, the United Nations Conference on Sustainable Development convened in Rio de Janeiro from 4 to 6 June 2012, referred to as Rio +20 , dedicated to the topics of Green Economy and Governance.

In this paragraph, the state of play of Local Agenda 21 in the two countries involved in the project ACTI.VE is reported. 
In Italy, Agenda 21 was born in the late 1990s and has developed rapidly, even though the state of activation is concentrated in the early stages rather than the intermediate phase (formation of the permanent Forum, problem analysis) or the advanced one (definition of the local action plan and monitoring).

The activation of Agenda 21 has occurred largely in the municipalities, predominantly in the northern regions. In particular, the largest number of active bodies is located in Emilia Romagna and Lombardy where Agenda 21 Regional Coordination was set up the. The Network of Local Agenda 21s in Tuscany was set up in July 2002, in Umbria the Agenda 21 Local Coordination was born in November 2003 and in Sicily in July 2007 [4].

In France the processes of Agenda 21 are 19 at a regional level equal to approximately $86 \%$ of all French regions, 40 at departmental level, just over a third of French departments, and 107 inter-municipal levels.

At a municipal level it follows that over 372 French cities and towns of all regions are engaged in a process of Agenda 21 [5].

The status of adherence to Agenda 21 in Italy and France for the various levels of government and territories is reported in fig. 2 .
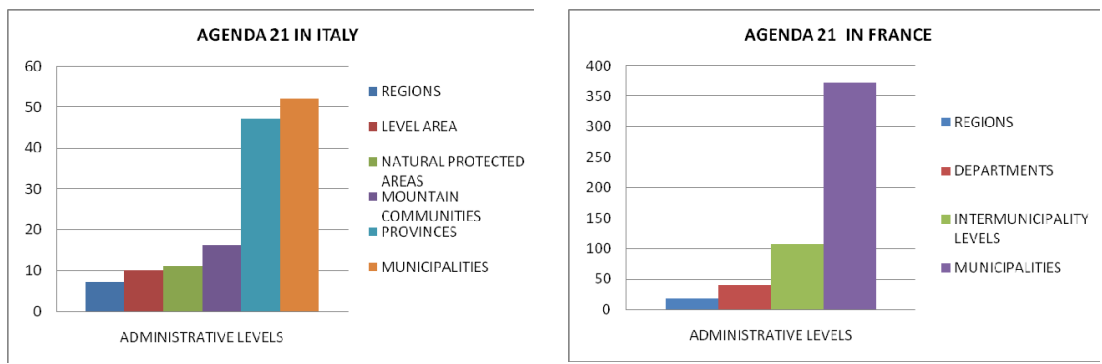

Figure 2: $\quad$ Status of adherence in Italy and France.

The general principles that guide the implementation of the cross border Agenda 21, within the ACTI.VE project can be summarized in the principle of a "joint project" in order to achieve both the overall aims and the specific objective.

Participation then becomes the basis of strategic and operational project. This type of approach enables us to appreciate the contributions of all partners and their respective capabilities, experiences and expertise.

This issue is not only an essential prerequisite for the progress of the project but also a guarantee for its validation [6].

\section{Methodological approach for a cross border Agenda 21 as a strategic tool for sustainability}

From a cognitive analysis (analysis of the state of the art of Agenda 21, at different levels of scale and the best practices existing) carried out at international level, especially in Italy and France, four key topics have emerged within the urban realities: waste, mobility and transport, energy and tourism. It is fundamental to consider these topics as part of an Environmental Action Plan 
within the Agenda 21 process and define best practices able to improve existing levels of sustainability.

The research has therefore focused on the term "best practice", the investigation of such actions in various territorial contexts and the feasibility of applying this "best practice" in the different fields; consider, for example, an urban context and the different characteristics tied to its dimensions: small towns, medium-large cities or metropolis [7].

It can therefore be said that each best practice is "a product of its own territory" and therefore cannot be presented again "tout court" in another geographical area, suitable solutions in some territories will not necessarily be effective in others (because of different culture, tradition, local development, etc).

In accordance with the above, a specific analysis has been developed for the four areas mentioned above. In this regard, in order to understand the underlying logic of a good practice, different levels of scale were considered: the regulatory framework, the administrative, managerial and operational competences, environmental state.

Subsequently, in accordance with the "participatory" approach, typical of the Agenda 21 process, we developed a methodological approach which could appreciate the contributions of all partners involved in the project in order to adapt the best practices in the territory concerned.

For this purpose a questionnaire was drawn up (for the four topics: waste, mobility and transport, energy and tourism) aimed at identifying practical actions at different levels of scale (especially municipal), and at a later stage to lay down "applicability thresholds".

Identifying the latter is crucial these days in order to support the public administration in choosing the actions of planning, management and development (as well as monitoring) most suitable to their respective areas of expertise. Each questionnaire provides for three different parts.

The first part is general (Part 1 - Table 1), in which have been identified the best practices existing in the cooperation area concerning the topic considered. In this regard, based on the cognitive analysis carried out previously, some of the most common best practices in literature have been suggested.

Part 2 is more detailed (Table 2) indeed for each best practice identified in the territory investigated, further details are provided regarding "characteristic parameters", such as range, existing agreements between neighbouring municipalities, affordability thresholds economic, social and environmental, what encourages/discourages this type of action, costs, objectives and expectations,... These parameters are fundamental to determining applicability thresholds for best practices with regard to different territorial contexts.

Given that in the research carried out, the topic of waste has played a significant role, while filling out the questionnaire, attention was paid to the actions of greater impact. Moreover, if you want to achieve meaningful goals such as "zero waste" - a strategy that encourages the redesign of resource life cycles so that all products are reused - (any trash sent to landfills and incinerators is minimal) should identify those which are the thresholds of 
convenience (in terms of the gravitational radius of the report service-users) and environmental and economic feasibility.

Table 1: $\quad$ Extract from the questionnaire prepared for the issue of waste: Part 1.

\begin{tabular}{|c|c|c|c|}
\hline TOPIC & \multicolumn{3}{|l|}{ WASTE } \\
\hline \multicolumn{4}{|c|}{ Part 1: WHAT IS BEING DONE (Best Practices) } \\
\hline \multirow{18}{*}{$\begin{array}{c}\text { TYPE OF ACTION (1) } \\
\text { Identify the good practices } \\
\text { existing in the area } \\
\text { examined (select among } \\
\text { the GP suggested) }\end{array}$} & & Ic & $\mathbf{P}$ \\
\hline & a.Waste separation with bins on the street & & \\
\hline & b.Waste separation home ("door to door") & & \\
\hline & c.Green Public Procurement & & \\
\hline & d.Domestic composting & & \\
\hline & $\begin{array}{c}\text { e.Awareness campaigns using tap water, local water } \\
\text { sources }\end{array}$ & & \\
\hline & f. Detergents and/or food on tap & & \\
\hline & g.Ecosagre -Ecofeste & & \\
\hline & h.Diapers and/or absorbent ecological & & \\
\hline & i. Market of exchange and reuse & & \\
\hline & j. Use of biodegradable materials in the canteens & & \\
\hline & k.The short chain & & \\
\hline & 1. Raising Awareness of the canvas bag for shopping & & \\
\hline & m. Collection of batteries and/or expired medicines & & \\
\hline & n.Empties & & \\
\hline & o.Using recycled paper & & \\
\hline & p.Stop advertising on tape & & \\
\hline & $\mathrm{q} \ldots .$. & & \\
\hline $\begin{array}{l}\text { - What actions are being } \\
\text { taken? (in addition to } \\
\text { those listed above) (1a) }\end{array}$ & $\ldots \ldots \ldots$ & & \\
\hline $\begin{array}{l}\text { - What are you going to } \\
\text { take? (in addition to those } \\
\text { listed above) (1b) }\end{array}$ & $\cdots \cdots$ & & \\
\hline
\end{tabular}

Table 2: $\quad$ Extract from the questionnaire prepared for the topic of waste: Part 2.

\begin{tabular}{|c|c|}
\hline \multicolumn{2}{|l|}{$\begin{array}{c}\text { Part } 2 \text { BEST PRACTICES - Insights } \\
\text { (to be completed for each best practice identified in Part 1) }\end{array}$} \\
\hline Title, description and evolutionary trends (2) & $\ldots \ldots$ \\
\hline Differentiated waste (2.1) (valid for good practice a and b) & \\
\hline Percentage achieved of differentiated/total (valid for good practice a and b) (2.2) & .. \\
\hline Range - reference scale $(\mathbf{2 . 3})$ & $\ldots$ \\
\hline Reasons that led to the selection of this best practices (2.4) & .. \\
\hline Threshold of economic viability, social, environmental, ....? (2.5) & $\ldots$ \\
\hline What encourages this type of action? (2.6) & $\ldots$ \\
\hline What it discourages? (2.7) & $\ldots .$. \\
\hline From what is stimulated? Existence of government incentives/regional/local,. (2.8) & $\ldots$ \\
\hline Respect environmental value (2.9) & ........... \\
\hline Burden (2.10) & \\
\hline What expectations/outcomes are expected to achieve? targets and time (2.11) & $\ldots \ldots \ldots \ldots$ \\
\hline Other, add any items that are considered relevant (2.12) & $\ldots \ldots \ldots$ \\
\hline
\end{tabular}


Part 3 refers to the "transversality of the topic addressed with waste" therefore it is only present in the questionnaires relating to the mobility and transport, energy and tourism thematic. Potential transversality for the three topics can be: means of transport used to transfer waste to landfill; energy requirement to incinerate waste; the problem associated with the increase in waste during periods of increased tourist numbers.

It is interesting to propose sustainable solutions associated with issues previously mentioned (for example, in the first case to propose electrical means or the curbside collection which involves the use of smaller vehicles).

In support of the questionnaires, "Instructions" (Table 3) have been prepared, aimed to briefly describe the items to be included in order to facilitate the compilation and, above all, make it as much unambiguous and homogeneous as possible.

Table 3: Retrieved questionnaire: instructions.

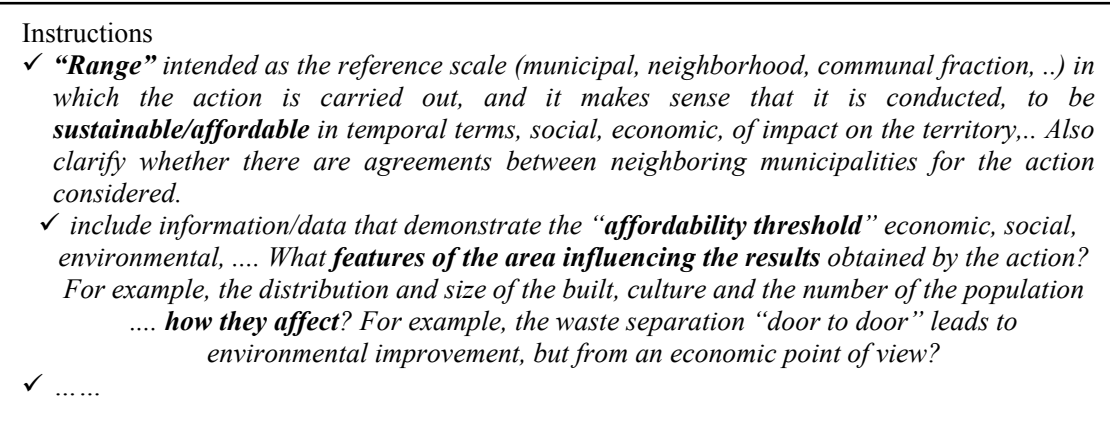

The methodological approach followed, as previously described, is based on "participation" at the different levels: initially addressed to actors within the partnership and, later, through forums (also supported by recent information technology) involves the external reality (population, actors public and private) [8].

Sharing experiences is, in fact, useful not only for territories that already have an Agenda 21 but also for areas that are approaching this initiative (as is happening for the Departement de la Corse du Sud), by encouraging them and by directing them to a sustainable management of resources. For this reason, the Network that has been activated within the project will be open to other territories in order to learn excellence, rework them (by adapting to cross border) and then spreading it. Following the analysis carried out, a database was prepared on the best practices (related to the four topics considered) at different levels of scale (regional, provincial, a consortium of municipalities, mountain communities, municipal, urban). Table 4 shows a draft of that database on best practices at an urban level. The next step was to identify, for the project area, the "practice more sustainable" for the four thematic, also considering the analysis carried out starting from the existing experiences in the scientific literature and the general characteristics of the territory in the regions of Liguria, Tuscany and South Corsica. 
Table 4: Database of good practices at an urban level for the four topics considered (excerpt).

\begin{tabular}{|c|c|c|c|c|c|}
\hline \multirow{2}{*}{ TOPIC } & \multirow{2}{*}{ TYPE OF GOOD PRACTICE } & \multicolumn{4}{|c|}{ CITY } \\
\hline & & Genoa & Pisa & Siena & ... \\
\hline \multirow{6}{*}{$\sum_{3}^{5}$} & Waste separation with bins on the street & Yes & Yes & Yes & $\ldots$ \\
\hline & Waste separation home ("door to door") & $\begin{array}{l}\text { Some } \\
\text { areas }\end{array}$ & Yes & $\begin{array}{l}\text { Historic } \\
\text { centre }\end{array}$ & $\cdots$ \\
\hline & Domestic composting & Yes & Yes & No & $\ldots$ \\
\hline & Ecosagre -Ecofeste & Yes & Province & Province & $\ldots$ \\
\hline & Market of exchange and reuse & Yes & No & No & $\ldots$ \\
\hline & Collection of batteries and/or expired medicines & Yes & Yes & Yes & $\ldots$ \\
\hline \multirow{8}{*}{ 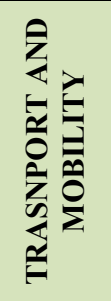 } & General Urban Traffic Plan & No & Yes & Yes & $\ldots$ \\
\hline & Municipal action sustainable mobility Plan & Yes & no & Yes & $\ldots$ \\
\hline & Cycling Plan (Soft Mobility) & No & Yes & no & $\ldots$ \\
\hline & Area with limited traffic and pricing policies & Yes & Yes & Yes & $\ldots$ \\
\hline & $\begin{array}{c}\text { Bike sharing, Biciplan, Bicycle and Mobility } \\
\text { Card }\end{array}$ & Yes & Yes & $\begin{array}{c}\text { in } \\
\text { definition }\end{array}$ & $\cdots$ \\
\hline & Car sharing and car pooling & Yes & Yes & Yes & $\ldots$ \\
\hline & Piedibus & Province & Yes & No & $\ldots$ \\
\hline & Block of traffic & No & Yes & No & $\ldots$ \\
\hline \multirow{5}{*}{ 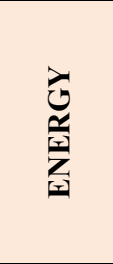 } & $\begin{array}{c}\text { Preparation of studies and municipal energy } \\
\text { Plans }\end{array}$ & No & No & No & $\ldots$ \\
\hline & Other Plans & SEAP & PIER & PEP & $\ldots$ \\
\hline & Renewable energy installations & Yes & Yes & Yes & $\ldots$ \\
\hline & $\begin{array}{c}\text { Criteria and technologies for energy efficiency } \\
\text { in the PRG }\end{array}$ & Yes & Yes & Yes & $\cdots$ \\
\hline & $\begin{array}{l}\text { Installations of photovoltaic systems on roofs of } \\
\text { public buildings }\end{array}$ & Yes & Yes & Yes & $\cdots$ \\
\hline \multirow{4}{*}{ 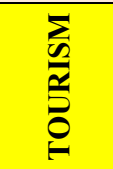 } & Creation of green way & Yes & Yes & Yes & $\ldots$ \\
\hline & Facilities of alternative tourism & Yes & Yes & Yes & $\ldots$ \\
\hline & Enhancement of local heritage & Yes & Yes & Yes & $\ldots$ \\
\hline & $\begin{array}{l}\text { Identification/construction of facilities/routes } \\
\text { for people with reduced mobility }\end{array}$ & Yes & Yes & Yes & $\cdots$ \\
\hline
\end{tabular}

For the issue of waste, the curbside collection turns out to be the most appropriate. In fact, it creates a sort of equilibrium in the medium term, including an increase in employment (social advantage) and a reduction in transporting waste to landfills or incinerators usually located out of the Municipality, because it is collected and reduced from the beginning (environmental benefits and economic benefits). Associated with this practice, however, information and an awareness of the people involved is needed, whether resident or tourist. The cooperation area is indeed characterized by a high number of tourists, and therefore a significant seasonal increase in population, not properly considered within the available statistics (ISTAT, Ispra) which leads to an incorrect evaluation of the waste production per head.

For the topic of mobility and transport, the most widely used practice, appears to be the achieving of cycling networks. Considering more specifically cities of medium-large dimension, such as provincial capitals, bike lanes are certainly a good practice to be provided in a soft mobility, but actions aimed at more structural planning are necessary. For example, the introduction of a bike-sharing 
service and the enhancement of a local public transport network primarily intended for: increasing the quality of service (revisiting old vehicles, accessibility, introduction of electric vehicles, or less environmental impact) and improving the intermodal transport among the local network and the suburban; creating interchange parking among the private vehicles and public transport and introducing integrated pricing.

Table 5: Characteristic parameters and benefits for good practices of the four topics considered good.

\begin{tabular}{|l|c|c|c|c|}
\hline \multicolumn{5}{|c|}{ 4 SUSTAINABLE GOOD PRACTICES } \\
FOR THE COOPERATION AREA
\end{tabular}


For the topic of energy, the "preparation of studies and municipal energy plans" turns out to be the good practice able to coordinate the different actions in the individual administrative realities. For example, the following actions: improvements to municipal buildings, public lighting, municipal areas with realizations of clean energy systems, review of existing building codes; can be integrated into a municipal energy plan. In the end, with regard to tourism, the "creation of a green way", of different types (paths sporting, gastronomic, historical) turns out to be adaptable to the different scales of reference.

Regarding this, the results obtained for each of the four best practice proposed are summarized in Table 5. In particular, those parameters that justify the choice, as applicable, generally to the cross-border territory, and specifically to local realities are reported [6].

\section{Conclusions}

Within the research was set a "general abacus" which summarizes objectives, actions, indicators and best practices. This document can become a tool to support the Action Plan on Transboundary (APT), to be shared in forums, in a process of a cross border Agenda 21. As outlined above, this approach is valid for different levels of scale, and in particular to an urban level in order to programme, plan, coordinate and manage the choices to be taken. Therefore the Agenda 21 process, considering the topics of major impact and their interrelationships, is able to relate the several existing urban plans and, in particular, identify which of these is more effective to deepen (or better specify) the different actions to be taken at the local level. In such a view, the Action Plan on Environment becomes the strategic tool through which Local Agenda 21 is able to plan, develop and manage a really sustainable city.

\section{References}

[1] Linee guida per le Agende 21 locali, http:/www.sinanet.isprambiente.it/it/ gelso/presentazione/svilupposost/Linee\%20guidaA21L2000.

[2] Pirlone F. (in press) "Il Piano di Azione Locale come strumento di supporto per pianificare in modo sostenibile", in VI Giornata di Studi INU "Città senza petrolio", Napoli.

[3] APAT Agenda 21 locale 2003 Dall'Agenda all'Azione: linee di indirizzo ed esperienze, 2004.

[4] Coordinamento nazionale agende 21 locali italiane, http:/www.a21italy.it/ IT/index.xhtml

[5] Comité 21, http://www.agenda21 france.org/

[6] Pirlone F., Sotgia Z., Spadaro I., Ugolini P., Analisi comprendente quattro buone prassi di sviluppo sostenibile identificate a livello di programma, Deliverable 1 in Progetto ACTI-VE Programma Transfrontaliero Marittimo Italia-Francia, 2007-2013, pp. 1-380, 2011.

[7] UNCED Rapporto Brundtland, 1987.

[8] Ugolini P. "Approccio alla sostenibilità nella governance del territorio", Collana Città e Territorio, FrancoAngeli Editore, Milano, 2010. 


\section{Annex}

F. Pirlone. The author has taken care of the Agenda 21's approach as a strategic tool for planning, development and management aimed at a sustainable city and, in particular, she has performed the cognitive analysis on the best practices, existing at an urban level, in the cooperation area in order to arrange a dedicated database.

Z. Sotgia. The author has managed the part relating to the Local Agenda 21 in Italy and France and their state of play. She has performed the study on best practices existing on the municipal waste, central topic within the ACTI.VE project. She also identified the best practices with relative questions to be included in the questionnaires.

I. Spadaro. The author has treated the setting of the abacus aimed at the schematization the objectives, actions, indicators and best practices, as starting point for a Action Plan on Transboundary (APT), and in particular, she has highlighted, for each the four best practice proposed, the characteristic parameters, which justified their choice.

P. Ugolini. The author, scientific coordinator from university for the project, has edited the conceptualization and description of the Agenda 21 process. In this perspective he has highlighted how information, awareness, communication and training are essential steps of the participatory process, as becoming aware both for the individual and for the community, inherent in the Agenda 21 process. 